\title{
Vibrações Brasileiras: Repertório brasileiro para vibrafone solo.
}

\section{Ronan Gil de Morais}

(Universidade de Estrasburgo)

\begin{abstract}
RESUMO: No Brasil, trabalhos anteriores enfocaram certos aspectos específicos da pesquisa relacionada ao vibrafone. Porém, o repertório local, o desenvolvimento próprio do instrumento no país e os músicos que se dedicaram a ele não foram objeto de estudo acadêmico. Assim, alguns elementos serão aqui abordados e discutidos, como: as peças brasileiras específicas para vibrafone solo, os compositores que se ativeram a escrever e os instrumentistas que se dedicaram a tal instrumento e tal literatura. O presente artigo apresenta então um levantamento de composições originais de autores brasileiros para vibrafone solo e elabora um panorama histórico de músicos que desempenharam uma contribuição importante para o instrumento no cenário nacional.
\end{abstract}

PALAVRAS-CHAVE: vibrafone; percussão; história da percussão, repertório para percussão.

BRAZILIAN VIBRATIONS: BRAZILIAN REPERTOIRE FOR VIBRAPHONE SOLO

ABSTRACT: In Brazil, previous works have focused on specific aspects of research on the vibraphone. However, the local repertoire, the development of the instrument in this country and the musicians who have dedicated themselves to it have not been an object of academic study. Thus, some elements will be addressed and discussed here, such as: the Brazilian scores specifically written for solo vibraphone, the composers who have written and the musicians who have dedicated themselves to such instrument and such literature. This paper presents a list of original compositions by Brazilian authors for solo vibraphone and prepares a historical overview of musicians who have played an important role for the development of the instrument on the national scene.

KEYWORDS: vibraphone; percussion; history of percussion; repertoire for percussion.

\footnotetext{
* Parte do trabalho agraciado com o Prêmio de Excelência em Pesquisa - IA/UNESP 2010
} 


\section{Introdução}

O vibrafone é um instrumento de percussão surgido no início do século $\mathrm{XX}$ e que foi incorporado ao repertório orquestral, camerístico e solista durante o decurso do mesmo. A criação, o surgimento e uma boa parte de seu desenvolvimento se dão nos Estados Unidos no início do século passado, como discutido em Howland (1977a e 1977b), Frisch (2002) e Chaib (2007 e 2008), dentre outros.

A exigência do domínio das técnicas de dampening e pedaling influenciou novas expressões fraseológicas e tipos de articulação na música para percussão, o que chamou a atenção para as novas possibilidades que surgiram advindas desse instrumento. Isso fez com que ele merecesse também uma atenção especial em trabalhos sobre o processo de estudo e de desenvolvimento técnico de suas possibilidades e recursos musicais, como abordado em Burton (1973), Tachoir (1984), Piltzecker (1988) e Rackipov (1998). É ainda um instrumento para o qual uma série de técnicas estendidas foi criada e adaptada (Smith, 2009a e 2009b) e a interação com meios eletrônicos foi possibilitada (Gartner, 2007), tornando seu repertório diversificado e dinâmico. A ênfase e crescente aumento no repertório solo para vibrafone ocorreu como consequência das características individuais que o instrumento foi adquirindo ao longo de seu processo de criação e contínuo desenvolvimento.

No Brasil, Boudler (1983 e 1987) e Hashimoto (1998) fazem menção ao repertório para vibrafone solo em seus trabalhos de catalogação de obras brasileiras para percussão. Porém, em meio a uma vasta literatura nacional para percussão, o repertório específico para vibrafone fica difuso e disperso no meio de uma série de outras informações. Em outro trabalho brasileiro, Souza (1994) aborda aspectos técnicos do vibrafone e propõe uma série de exercícios de aprimoramento prático no instrumento. Tarcha (1997) também propõe uma série de exercícios práticos, enfocando especificamente a técnica de duas baquetas. Chaib (2007) faz uma análise dos aspectos timbrísticos do instrumento e aborda a obra Cálculo Secreto de José Manuel López López (Portugal). Mesmo contribuindo 
enormemente à literatura para vibrafone, essas referências acabam citando pouco material brasileiro e, no que se refere aos instrumentistas que se dedicaram ao vibrafone no Brasil, muito pouco foi trabalhado, discutido e analisado.

Em função desse panorama algumas perguntas surgem: Quando começaram a ser escritas peças específicas para vibrafone solo no país? O que foi escrito? Quais foram os compositores que se ativeram a escrever? O que se tem atualmente como repertório nacional para o instrumento, em termos quantitativos e qualitativos? Quem são os instrumentistas que desempenharam contribuição importante para tal instrumento e tal literatura?

No Brasil, aspectos como a introdução e o histórico de desenvolvimento do vibrafone no país, bem como seu repertório local e os músicos que se dedicaram a ele, não foram objeto de estudo acadêmico. Trabalhos anteriores deram enfoque a outros aspectos da pesquisa relacionada ao instrumento, mostrando a relevância do presente artigo. Assim, têm-se como objetivos: realizar um levantamento de partituras e composições originais de autores brasileiros para vibrafone solo nas instituições de ensino musical, bibliotecas, acervos públicos e particulares do país, bem como entrevistar vibrafonistas e músicos que se dedicaram ao instrumento no cenário nacional. Procura-se assim preencher a grande lacuna existente nas informações sobre material para percussão solo no Brasil, constituindo o primeiro trabalho focado especialmente sobre o repertório solista para vibrafone.

Para alcance dos objetivos propostos, o método empregado foi dividido em dois enfoques distintos: a pesquisa bibliográfica e documental (para aquisição das partituras e composições) e a elaboração de entrevistas (para aquisição de informações junto aos músicos).

\section{Resultados e Discussão}

Todos os dados referentes às partituras encontradas foram compilados na Tabela 1 que mostra a relação de peças e compositores a partir do ano de composição com informações sobre a edição da partitura. 
Nesta tabela pode-se constatar então que a quantidade de obras brasileiras para vibrafone solo encontradas no presente trabalho é de 81 peças. Esse resultado somado não leva em conta algumas composições que são caracterizadas como conjuntos de peças. Então, se considerarmos as obras Seis Reflexões (P. Cameron), Duas Peças Breves (R. Victorio), Canções Infantis (R. Souza) - são 11 canções -, Pequena suíte para vibrafone (L. D’Anunciação) - 4 danças -, Quatro instantâneos (R. Victorio) e Prelúdios No. 1 a 5 (C. dos Santos) como sendo um conjunto de peças e contarmos suas partes independentemente, a quantidade saltará para 113 peças brasileiras.

Esse resultado é bastante grande e relevante se comparado aos dados de Howland (1977b), Boudler (1987), Hashimoto (1998) e Serale (2005). Howland (1977b) fez uma compilação de materiais norte-americanos para vibrafone em que incluiu obras originais, arranjos, transcrições e métodos, encontrando 60 títulos disponíveis. Vê-se que para o ano de 1977 no Brasil só haviam sido compostas as Seis Reflexões (1973), mas a quantidade de material subsequente passou a superar bastante essa marca registrada por Howland (1977b). Boudler (1987) e Hashimoto (1998) compilaram extenso material de compositores brasileiros para percussão incluindo obras para solista, camerista e solo com orquestra. A profusão de materiais é grande, incluindo não só as peças específicas para vibrafone, mas também para marimba, percussão múltipla, caixa clara, tímpano, grupo de percussão, etc. Boudler (1987) relata no total 212 obras no repertório para percussão existente até então e Hashimoto (1998) 338 obras compostas somente no Estado de São Paulo até 1998. Serale (2005) compilou o material para percussão solo de compositores argentinos e encontrou ao todo 73 peças (incluindo obras para marimba, vibrafone, tímpano, caixa e percussão múltipla) sendo somente 5 obras para vibrafone solo. A maior parte das obras por ele compiladas é para percussão múltipla (39\% das obras) e para marimba (38\%). Mas, se na Argentina a marimba parece ter então um papel de destaque entre os teclados de percussão, no Brasil o vibrafone parece ser o instrumento que se sobressai entre eles, o que será corroborado por outros motivos e outras explicações mais à frente. 
Os resultados do presente trabalho não podem ser comparados aos dados sobre composições brasileiras solo para outros instrumentos de percussão, porque estes ainda não foram realizados. Somente a reunião de materiais e partituras de peças para marimba solo, percussão múltipla, caixa e outros, poderá mostrar indicações mais precisas da diversidade de material brasileiro disponível.

Analisando a Tabela 1, a partir dos anos de composição das obras, podese observar alguns aspectos característicos para cada década desde a primeira peça escrita. A primeira peça brasileira composta para vibrafone solo é de 1973 e observa-se que esta obra aparece isolada para toda a década de 70. Depois, vê-se que para a década de 80 o número dá um salto para 8 peças. Essa década parece ser caracterizada por percussionistas que escreveram para vibrafone, seja como forma de estudo de composição ou como forma de desenvolvimento de aspectos técnicos individuais no instrumento. A única exceção para essa característica marcante está nas Duas Peças Breves de Roberto Victorio (segunda obra escrita para vibrafone no país, separada por 8 anos de distância da primeira), as outras peças são todas de pessoas ligadas diretamente ao estudo e à execução do próprio repertório que compuseram. Percebe-se então um salto gigantesco de número de composições para a década de 90 (com 35 peças no total). Salto esse que contrapõe também as características da década anterior, pois, se na década de 80 a tendência parece mostrar percussionistas compondo, na de 90, o nome de compositores que não necessariamente são instrumentistas ou percussionistas se sobressai entre os dados. O salto na quantidade de obras em 90 se deu em função do trabalho do instrumentista André Juarez que com seu projeto "Vibrafone solo" encomendou obras dos mais diferentes compositores com os quais teve contato. Realizou assim um extensivo trabalho de encomenda, gravação e estreia de obras, fazendo com que a quantidade e a diversidade de obras desse período saltassem marcadamente, sendo fruto de seu contato direto com os compositores.

Dentre as peças compostas nessa década têm-se Névoas e Cristais (1995) de Jônatas Manzolli para vibrafone e computador que, segundo Traldi (2007), aparece como a primeira obra brasileira para instrumento de percussão de teclado e sons eletrônicos ao vivo (live electronics). Também dedicada ao percussionista 
André Juarez, esta obra é baseada em um diálogo entre o vibrafone e o computador que gera eventos MIDI em tempo real.

Para os dados a partir de 2000 (com 31 peças no total) pode-se constatar certa estabilização em relação às décadas anteriores. Se até a década de 90 os dados pareciam mostrar uma tendência de aumento gradativo, depois de 2000 percebe-se que esses dados não saltam mais exponencialmente. A tendência de crescimento das décadas de 80 e 90 não chega a cair, mas se estabiliza notadamente.

Quando se compara a quantidade de peças brasileiras encontradas (81 peças) com aquelas que chegaram a ser editadas (11 peças, 13,60\% do total), nota-se como estas representam uma parte pequena do total. A proporção de peças publicadas que pode ser encontrada em editoras e casas editoriais de ampla divulgação pode resultar em certa dificuldade de acesso a essas partituras. A divulgação desse material acaba ocorrendo muitas vezes de compositor a instrumentista ou de instrumentista a instrumentista, ou seja, através de pessoas que conhecem, tocam e/ou incluem esse material em seu repertório. A ênfase, quando se fala de repertório para vibrafone, é dada principalmente para literatura estrangeira e material que vem de fora do país. Mas se a quantidade de peças brasileiras agora se mostra considerável, poderia ser a não edição dessas partituras um dos fatores responsáveis pela dificuldade de acesso a elas?

$\mathrm{Na}$ Argentina, alguns fatores parecem apontar para a mesma problemática no tange à divulgação do material local. Como Serale (2005) afirma, “os problemas começam já no momento de obter as partituras: o material nas bibliotecas musicais de Buenos Aires é praticamente nulo e o que é utilizado na formação em conservatórios raramente inclui música argentina. A principal fonte de partituras é o intercâmbio entre colegas e o contato com os próprios compositores. Disso vem o grande desconhecimento do material existente, sua escassa circulação e a pouca frequência com que as obras são executadas." 


\subsection{Acessibilidade e fabricação nacional do instrumento}

Vários são os motivos que parecem contribuir para a relevância dos resultados anteriores e fizeram com que o vibrafone encontrasse tamanha expansão e difusão no Brasil, podemos citar entre eles a fabricação nacional do instrumento. Se o instrumento pode ser encontrado em fábricas nacionais (em algumas há bastante tempo), o acesso a ele passou a ser maior (possibilitado pela facilidade que se cria de encontrá-lo, de negociar preços, formas de pagamento, transporte e outros custos) e a possibilidade de comprá-lo em moeda nacional possivelmente facilitou também a sua aceitação e a sua grande expansão, com consequências nítidas sobre seu repertório.

Uma das empresas que fabricam o instrumento foi criada oficialmente em março de 1959. Segundo as próprias palavras de Luiz Guilherme, atual proprietário da empresa (Comunicação Pessoal, 2009):

Não temos um registro preciso, mas creio que a empresa foi oficializada justamente porque o vibrafone, como um instrumento de maior valor levou a isso. Então os primeiros vibrafones devem ser de 1959. Tinham 34 teclas de Dó a Lá com motor. Por volta de 1980 tivemos os primeiros de Fá a Fá e sem motor. Nos últimos 10 anos, conseguimos as medidas intermediárias de barras de alumínio que permitiram termos atualmente 4 modelos.

Indagado sobre por que a fábrica começou a produzir vibrafones e sobre os momentos iniciais desse processo, respondeu:

O fundador da empresa, José Guilherme, viu um vibrafone numa loja de música e ficou encantado. Produziu um para uso pessoal e acabou passando a produzir para revenda.

A produção no inicio era de umas 30 peças/ano, focado em orquestras de baile, mas o advento dos teclados [eletrônicos] acabou reduzindo a procura. $\mathrm{O}$ instrumento voltou mais focado nos percussionistas que buscam instrumentos de teclado, principalmente com o crescimento dos cursos via conservatórios, universidades e outros centros de ensino. 
Beto Caldas, vibrafonista que trabalhou com diversos grupos brasileiros, acabou se associando à Jog, contribuindo muito também para que a empresa entrasse num novo momento de produção e investisse ainda mais para produzir vibrafones de boa qualidade. Nas palavras de Luiz Guilherme:

O Beto dava aulas de bateria e vibrafone na ULM, mas a falta de instrumento para as aulas e para os alunos impedia o desenvolvimento. Em parceria, iniciada ali pelo ano 2000, ele contribuiu para que pudéssemos aperfeiçoar nosso modelo. Uma nova liga de alumínio forneceu o timbre adequado, trabalhamos os móveis, pedal, afinação. Uma dificuldade foi resolvida, pois o Beto, em 2002, dando aulas para o diretor de uma empresa metalúrgica, conseguiu que fossem produzidas medidas intermediárias dos tubos de ressonância e das barras das teclas, em quantidades compatíveis com nossa realidade, permitindo que chegássemos ao modelo Master com 4 larguras de teclas diferentes. Isso permitiu um equilíbrio melhor do volume do instrumento. Até um instrumento de 42 teclas com 5 larguras de teclas foi possível fazer.

Tivemos ainda apoio de diversos outros músicos para avaliações, comentários, sugestões, cedendo material sobre como afinar melhor o vibrafone, a marimba e o xilofone.

Houve uma diversificação dos produtores e distribuidores, sendo que atualmente diferentes empresas, fábricas e luthiers estão produzindo o instrumento em distintas regiões do país.

\subsection{Os instrumentistas}

“. . I I don't think instruments make contributions. Players do."

Gary Burton (1973).

Se a fabricação do instrumento possibilitou maior acesso ao vibrafone no Brasil, é importante acima de tudo salientar e mostrar a relevância da atuação de percussionistas e compositores que marcaram o histórico de seu desenvolvimento. Por isso a discussão será dirigida para a apresentação de alguns aspectos históricos sobre os músicos que contribuíram diretamente para sua difusão no país. Estes 
músicos serão descritos pela devida importância de atuação antes da década de 1970 até 2009.

\subsubsection{Antecedentes à década de 1970: Sylvio Mazzucca $(* 1919,+2003)$}

Instrumentista importante no cenário brasileiro da música para rádio, televisão e bailes, começou sua carreira como regente de orquestra, pianista e compositor (na maioria dos casos de música instrumental). Na década de 50 e até o começo dos anos 60, Sylvio Mazzucca foi regente da big band mais solicitada para festas e bailes na capital paulista, fazendo também temporada no Rio de Janeiro e excursionando por outros países. Como afirmado em Albin (2009) iniciou sua carreira em 1932, tocando em São Paulo com a orquestra de Nicolino Leocatta. Em 1938 passou a atuar na orquestra da Rádio Tupi e em 1942 também na Rádio Difusora. "Nessa época, além do piano, passou a tocar vibrafone” (Albin, 2009). Gravou o primeiro disco com sua orquestra em 1950, pela Odeon e certamente é dele um dos primeiros registros fonográficos brasileiros do vibrafone.

Se Sylvio Mazzucca é responsável por boa parte da trajetória do vibrafone dentro do contexto popular camerístico e orquestral antes de 70, é em 1973 que será escrita a primeira obra para vibrafone solo brasileira.

\subsubsection{Década de 1970}

Pedro Cameron (*1948): Seis Reflexões, $1^{\text {a }}$ obra para vibrafone solo As Seis Reflexões foram compostas em 1973 e editadas em 1980 pela Editora Novas Metas. Elas formam um conjunto de seis peças curtas podendo ser tocadas em conjunto ou separadamente.

Segundo Hashimoto (1998), Cameron graduou-se em violão e atuou como professor da Faculdade Marcelo Tupinambá, do Conservatório de Tatuí e foi regente de diferentes orquestras pelo Estado de São Paulo. Em 1970 Cameron passou a dar aulas no Conservatório de Tatuí onde, em seguida, Cláudio Stephan 
também iniciou seu trabalho dando aulas de percussão. Foi nessa época que Stephan pediu a Cameron que escrevera uma peça para vibrafone, surgindo assim a Reflexão no.1 que, segundo o compositor, foi escrita "a título de experiência", já que ele não conhecia o instrumento. Depois de estudar essa primeira peça, Stephan pediu que ele continuasse o trabalho e encorajou-o a escrever mais ("eu tinha muita vontade de compor na época e acabei escrevendo uma série de seis peças" - Pedro Cameron - Com. Pes., 2009). Como o próprio compositor relatou:

eu nunca tinha ouvido o instrumento, tinha uma sonoridade na cabeça, tinha um som e um timbre em mente e escrevi pensando assim, mas quando eu ouvi pela primeira vez com a minha peça fiquei impressionado com aquela beleza de som.

Segundo Hashimoto (1998) e Eduardo Gianesella (Com. Pes., 2009) Stephan estreou a $1^{\mathrm{a}}$. Reflexão no Masp em 1974 e Eduardo Gianesella fez a primeira audição das Seis Reflexões em conjunto em 1986 em São João Del Rei (MG).

\section{Cláudio Stephan $\left({ }^{*} 1944\right)$}

Estudou piano com Sofia Mello Oliveira, trompa com Enzo Pedini e percussão com Ernesto de Lucca. Como músico profissional, começou ainda jovem como trompista da Orquestra Sinfônica Municipal de São Paulo (OSMSP). Motivos de saúde levaram-no a deixar a trompa e continuar a carreira como percussionista, assumindo depois o cargo de timpanista titular da OSMSP. Fundou e organizou o Grupo de Percussão do Conservatório Brooklin Paulista, que recebeu, em 1975, o prêmio da Associação Paulista dos Críticos de Arte (APCA).

Ele é o responsável pela encomenda da primeira peça para vibrafone solo e acabou trabalhando estreitamente com Cameron.

Quando eu comecei a tocar [vibrafone e teclados de percussão] eu já tinha boa leitura por causa do piano e da trompa, eu conhecia o teclado profundamente [...]

Naquela época se abriu muitas possibilidades pra mim no Brasil que era um país onde não tinha nada! Nada! Tinha o De Lucca com a sua ótima vontade, mas ele era timpanista e a gente foi assim pegando o facão e abrindo a 
picada, fazendo instrumento de teclado de percussão, baquetas, tudo que os alunos precisavam [...]

O Cameron que fez a primeira obra de vibrafone solo que eu conheço e acabou dedicando pra mim. Acho que antes era tudo transcrição..." (Cláudio Stephan - Com. Pes., 2008).

\subsubsection{Década de 1990: André Juarez (*1964)}

Oriundo de família de músicos começou a estudar piano com a mãe ainda criança, depois violino e aos 10 anos bateria. Mais tarde teve acesso aos LPs dos vibrafonistas Milt Jackson, Mike Manieri e Gary Burton, e acabou decidindo por estudar teclados de percussão. Estudou percussão na Universidade do Estado de São Paulo e vibrafone na Berklee College of Music com Gary Burton. Deu aula na Universidade de Campinas na década de 90 onde concluiu o mestrado com trabalho sobre aspectos técnicos no vibrafone (Souza, 1994). Sobre esse e outros momentos de sua carreira (inclusive sobre o projeto "Vibrafone Solo") relata:

Meu mestrado foi muito técnico, e depois eu quis pôr em prática [...] Pensei: vou montar um trabalho com vibrafone, montar um repertório de estudo de vibrafone, pra ver quais são as possibilidades do instrumento [...]

Eram mais de 50 músicas, foi muita música que encomendei na época, tem peças que não estão nos meus CDs. Era uma época de introspecção total, tava mergulhado naquilo [...]

Eu era muito louco porque foi um trabalho que eu não ganhei um centavo com isso [...] A coisa das peças foi isso, falei: vou pôr em prática o que eu aprendi no meu mestrado... aprendi muita coisa, conheci muitos amigos, fiz muitos contatos... (André Juarez - Com. Pes., 2009).

Boa parte do repertório se deve ao trabalho desse músico em encomendar, comissionar e trabalhar as obras (predominantemente da década de 90) junto aos compositores com os quais pôde ter contato. 


\subsubsection{Década de 2000 a 2010: Augusto Moralez (*1980)}

Iniciou sua carreira tocando bateria em grupos de música tradicional brasileira. Cursou Especialização com Emmanuel Séjourné no Conservatório de Strasbourg (França) e Bacharelado em percussão pela Universidade do Estado de São Paulo. Como integrante do Duo Percosur recebeu o Prêmio Ady Mootz no International Percussion Competition (2009) em Luxemburgo.

O destaque de Augusto Moralez para a década de 2000 a 2010 está na profusão de peças que acabou encomendando dos mais diversos compositores. Entre essas encomendas de novas obras para vibrafone solo pode-se destacar: Tetragrammaton VI (2006) de Roberto Victorio, Devaneio (2006) de Dimitri Cervo, Abstrações I (2007) de Ivan Chiarelli Monteiro, Entre o pesar e a leveza (2007) de Arthur Rinaldi (que está em vias de finalizar outra obra para vibrafone para o intérprete) e Solitude (2008/2009) de Samuel Peruzzolo (que acabou Ihe dedicando quatro outras obras para as formações as mais diversas).

A encomenda de peças por André Juarez durante a década de 90 tem semelhanças com a proposta de Augusto na década posterior. Ele procurava acima de tudo expandir e tocar esse repertório, divulgando-o em concertos ao vivo. Quando perguntado sobre a motivação que o levou a encomendar as peças, respondeu:

Eu decidi encomendar essas peças porque considero o repertorio para vibrafone muito reduzido, não existem muitas obras para se escolher. Eu sinto que nós como percussionistas temos o dever de trabalhar para que os compositores passem a compor cada vez mais para percussão. Sinto também que os compositores escrevem de forma espontânea para instrumentos como piano ou violino, o que não acontece com o vibrafone. É preciso 'ficar no pé', fazendo pressão para que eles escrevam para percussão, em especial para vibrafone (Augusto Moralez - Com. Pes., 2009). 


\section{Conclusões}

A amostragem de peças brasileiras aqui relacionadas é considerável e demonstra o grande interesse que o vibrafone suscitou entre intérpretes e compositores durante os diferentes momentos históricos pelos quais passou no Brasil. A presente compilação não é determinante e tácita em afirmar que tudo já composto neste país para o instrumento está aqui relacionado, mas a listagem atual é aproximativa (ao que realmente pode ser encontrado) e bastante representativa do panorama atual de composições para vibrafone.

Vários aspectos mostrados aqui explicam o grau de relevância do instrumento no Brasil. Associado a isso foi mostrado também o trabalho de diversos instrumentistas que se dedicaram e se dedicam ao instrumento, sendo os principais agentes de transformação de todo o panorama.

Em função de todos os elementos e características aqui apresentados, pode-se concluir também que, atualmente, o vibrafone possui uma abrangente difusão entre músicos, intérpretes e compositores brasileiros. Mas o seu repertório parece ser muito pouco conhecido:

... considero o repertorio para vibrafone muito reduzido, não existem muitas obras para se escolher." (Augusto Moralez - Com. Pes., 2009).

[O repertório para vibrafone solo] "Ainda é muito pequeno, eu acho! Pela própria tradição de percussão no Brasil, onde é muito difícil você querer ser um solista de um único instrumento. Profissionalmente pra você sobreviver sendo vibrafonista ou marimbista, só tocá um teclado, é uma coisa muito difícil [...] O repertório é tão rico e um naipe tão fabuloso quanto o da percussão que você tem milhões de timbres, de possibilidades, enfim você precisa de cinco vidas pra conseguí tocar tudo decentemente, se especializá num repertório não é tão interessante... Acho que em função disso a maioria dos percussionistas eu, Carlos Tarcha, Ricardo Bologna, Eduardo Leandro... Acho que não houve muita demanda por um repertório de vibrafone solo, entendeu? Por isso que não se constituiu, enfim, acho que é isso... Joaquim Abreu (Com. Pes., 2009).

Comentários como o de Augusto Moralez e Joaquim Abreu (músicos que conhecem e tocam peças disponíveis) mostram que infelizmente somente uma 
ínfima parte do repertório ainda é conhecida, divulgada, tocada e, acima de tudo, tornada acessível. Estes talvez sejam os grandes desafios atuais para com 0 repertório que já foi escrito: divulgá-lo e torná-lo acessível. É por isso e com esse intuito que o presente trabalho se presta a citar todos os materiais e peças aqui mencionados. Todos os aspectos aqui trabalhados são fruto de três anos de pesquisa e estão mais profundamente discutidos em MORAIS (2009). Para que este trabalho pudesse ser realizado agradecemos imensamente a contribuição de todas as pessoas aqui mencionadas, bem como os inúmeros compositores, músicos e colaboradores com os quais tivemos contato.

Demais trabalhos poderão enfocar outros instrumentos de percussão (marimba, percussão múltipla, entre outros) no que tange ao seu repertório (solista ou camerístico) e suas considerações históricas no Brasil ou demais países. Tais trabalhos serão indicadores da diversidade de material musical disponível e facilitadores de novos processos de interpretação e de relação compositor/intérprete, possibilitando ainda acréscimo à discussão musicológica e de outros pesquisadores.

\section{Referências}

ALBIN. Dicionário Cravo Albin da Música Popular Brasileira. Disponível em: $<$ http://www.dicionariompb.com.br/detalhe.asp?nome = S\%EDlvio + Mazzuca\&tab ela $=$ T_FORM_A\&qdetalhe $=$ art $>$. Acesso em: 1 nov. 2009.

BOUDLER, John E. Brazilian percussion compositions since 1953: An annotated catalogue. Tese de doutorado. Chicago: American Conservatory of Music, 1983.

BOUDLER, John E. Música erudita brasileira para percussão. Tese de Livre Docência. São Paulo: IA/UNESP, 1987.

BURTON, Gary. Evolution of Mallet Techniques.... 1973. Percussionist, vol. 10 , No. 3, Spring, 1973.

CHAIB, Fernando Martins de Castro. Exploração Tímbrica no Vibrafone: Análise Interpretativa da obra Cálculo Secreto, de José Manuel López López. Dissertação de Mestrado. Aveiro (Portugal): Universidade de Aveiro, 2007.

CHAIB, Fernando Martins de Castro. Let vibrate: Um breve panorama sobre o vibrafone na música do século XX. Opus, Goiânia, vol. 14, No. 1, p. 50-64, junho, 2008. 
FRISCH, Guy. Le vibraphone. Début et évolution de l'instrument à travers le XXe. Siècle. Luxembourg: 2002.

GARTNER, Kurt. Fernando Rocha: Performing with computer-based electronics. Percussive Notes, p. 86-89, October, 2007.

HASHIMOTO, Fernando A. de A. Catálogo de peças brasileiras para instrumentos de percussão, compostas no Estado de São Paulo até 1998. Relatório Final de Projeto Científico. Campinas: UNICAMP/FAPESP, 1998.

HOWLAND, Harold. The Vibraphone: A Summary of Historical Observations with a Catalog of Selected Solo and Small-Ensemble Literature. Percussionist, vol. 14, No. 3, Summer, $1977[a]$.

HOWLAND, Harold. The Vibraphone: A Summary of Historical Observations with a Catalog of Selected Solo and Small-Ensemble Literature, Part 2. Percussionist, vol. 15, No. 1, Fall, 1977[b].

MORAIS, Ronan Gil de. Repertório brasileiro para vibrafone solo. Trabalho de conclusão de curso. São Paulo: IA/UNESP, 2009.

PILTZECKER, Ted. Vibraphone Pedaling. Percussive Notes, vol. 26, No. 2, Winter, 1988.

RACKIPOV, Errol. Creative expression on vibes through pedaling and dampening. Percussive Notes, p.42-46, June, 1998.

SERALE, Daniel. Obras de compositores argentinos para un percusionista. Monografia. Argentina: Conservatório de Música Carlos López Buchardo, 2005.

SMITH, Joshua D. Extended vibraphone techniques in Deane's "Mourning Dove Sonnet". Percussive notes, p. 24-28, February, 2009 a.

SMITH, Joshua D. Extended vibraphone techniques in Deane's "The Apocryphal Still Life". Percussive notes, p. 56-58, April, 2009 b.

SOUZA, André Pinheiro de. Vibrafone: Guia de estudo. Dissertação de Mestrado. Campinas: UNICAMP, 1994.

TACHOIR, Jerry. Clarity in executing lines on the vibraphone through the use of dampening. Percussive Notes, vol. 23, No. 1, October, 1984.

TARCHA, Carlos. Técnica de duas baquetas para teclados de Percussão. Marimba, Vibrafone, Xilofone e Glockenspiel. Dissertação de Mestrado. São Paulo: USP, 1997.

TRALDI, César A. Interpretação mediada e interfaces tecnológicas para percussão. Dissertação de Mestrado. Campinas: UNICAMP, 2007. 


\section{Apêndice}

Tabela 1: Relação de peças, compositores e demais informações a partir do ano de composição.

\begin{tabular}{|c|c|c|c|c|}
\hline Ano & Título & Autor & Editora & Observações \\
\hline 1973 & Seis Reflexões & Pedro Cameron & $\begin{array}{l}\text { Ed. Novas } \\
\text { Metas }\end{array}$ & \\
\hline 1981 & Duas peças breves & Roberto Victorio & 1 & \\
\hline 1984 & Gender Barangan & José Luiz Martines & $\begin{array}{l}\text { Serviço de } \\
\text { difusão de } \\
\text { partituras/USP }\end{array}$ & \\
\hline 1985 & Pequena peça & Carmo Bartoloni & I & \\
\hline 1985 & $\begin{array}{l}\text { Lied (da Sonata Periods } \\
\text { of life) }\end{array}$ & Ney Rosauro & PRO-percussão & \\
\hline 1988 & Estudo & Carmo Bartoloni & l & \\
\hline 1988 & Bem-vindo & Ney Rosauro & PRO-percussão & \\
\hline 1989 & Entre outras coisas & Carmo Bartoloni & l & $\begin{array}{l}\text { São pedidas } \\
\text { campainhas } \\
\text { adicionais }\end{array}$ \\
\hline 1989 & Prelúdio & Draicor (Pseud.) & l & \\
\hline 1990 & Fogo & Carlos Stasi & l & \\
\hline 1990 & Imagens & Raul do Valle & l & \\
\hline 1990 & Processional & Victor Lazzarini & l & \\
\hline 1991 & Prelude \& Blues & Ney Rosauro & PRO-percussão & \\
\hline 1992-1993 & Passos & Marcel Cangiani & l & \\
\hline 1994 & Experimentação No. 1 & Cyro Pereira & l & \\
\hline 1994 & Ritmata No. 3 & Edmundo Villani-Côrtes & l & \\
\hline 1994 & Solo para vibrafone & Ernst Mahle & l & \\
\hline 1995 & Quase um Rondo & Gilberto Mendes & l & \\
\hline 1995 & Névoas e Cristais & Jônatas Manzolli & l & $\begin{array}{l}\text { Com live } \\
\text { electronics }\end{array}$ \\
\hline 1995 & Vibra(phone varia)tions & Luiz Henrique Xavier & l & \\
\hline 1995 & Solo III Op. 83 & Marlos Nobre & 1 & \\
\hline
\end{tabular}




\begin{tabular}{|c|c|c|c|c|}
\hline 1995 & Cançoneta & Osvaldo Lacerda & I & \\
\hline 1995-1996 & $\begin{array}{l}\text { Pequena Suite para } \\
\text { vibrafone }\end{array}$ & Luiz D’Anunciação & $\begin{array}{l}\text { Melódica } \\
\text { Percussiva }\end{array}$ & \\
\hline 1996 & Suíte para vibrafone & Eduardo Reck Miranda & $\begin{array}{l}\text { Goldberg } \\
\text { Edições }\end{array}$ & \\
\hline 1996 & Móbile & José Augusto Mannis & 1 & \\
\hline 1996 & $\begin{array}{l}\text { No. } 9 \text { - Presença de } \\
\text { Curupira }\end{array}$ & $\begin{array}{l}\text { Sérgio de Vasconcellos- } \\
\text { Corrêa }\end{array}$ & l & \\
\hline 1996-1997 & Remelexo & Alberto Trindade & I & \\
\hline 1997 & Modelagem X-a & Edson S. Zampronha & $\begin{array}{l}\text { Ed. François } \\
\text { Dhalmann }\end{array}$ & \\
\hline 1997 & TransFormantes III & Flo Menezes & 1 & $\begin{array}{l}\text { Com live } \\
\text { electronics }\end{array}$ \\
\hline 1999 & $\begin{array}{l}\text { Oração para São } \\
\text { Francisco de Assis }\end{array}$ & João Catalão & l & \\
\hline$*$ & Harmonias & Almeida Prado & l & \\
\hline$*$ & Bag's & André Christovan & l & \\
\hline$*$ & Sinal Fechado & Arrigo Barnabé & l & \\
\hline * & Con Versus & Damiano Cozzella & l & \\
\hline$*$ & Edmundo Villani-Côrtes & André no frevo & I & \\
\hline * & Panta Rhei & $\begin{array}{l}\text { Hans-Joachim } \\
\text { Koellreutter }\end{array}$ & l & \\
\hline$*$ & Andrénito & Hermeto Paschoal & l & \\
\hline$*$ & Divertimento No. 1 & Laércio de Freitas & l & \\
\hline$*$ & Rose Bad & Lívio Tragtenberg & I & \\
\hline$*$ & Bola de gude & Mané Silveira & l & \\
\hline$*$ & Melodia & Nelson Ayres & l & \\
\hline$*$ & Laser & $\begin{array}{l}\text { Ricardo Breim e José M. } \\
\text { Wisnik }\end{array}$ & I & \\
\hline$*$ & Para André & Rogério Duprat & l & \\
\hline 2000 & Antípoda & João Catalão & l & \\
\hline 2000 & Prelúdio No. 1 & Mauricio Ribeiro & I & \\
\hline 2001 & Gary Burton & André Juarez & I & \\
\hline 2001 & Vibes etudes and songs & Ney Rosauro & PRO-percussão & \\
\hline
\end{tabular}




\begin{tabular}{|c|c|c|c|c|}
\hline 2001 & Tema & Samuel Peruzzolo & I & \\
\hline 2002 & Circle limit & $\begin{array}{l}\text { M. C. Lobatcheviski } \\
\text { (Pseud.) }\end{array}$ & I & \\
\hline 2002 & $\begin{array}{l}\text { Two Reflections for Solo } \\
\text { Vibraphone (Brazilian } \\
\text { Landscape and } \\
\text { Reflections on the New } \\
\text { World) }\end{array}$ & Ney Rosauro & PRO-percussão & \\
\hline 2002 & 11 Canções Infantis & Ricardo Souza & Kinko's & \\
\hline 2002 & III. & Samuel Peruzzolo & I & \\
\hline 2003 & Devaneio para vibrafone & Leonardo Margutti & l & \\
\hline 2003 & Miniatura de um frevo & Wellington das Mercês & I & \\
\hline 2004 & Devaneio & Dimitri Cervo & l & \\
\hline 2004 & No cais & Mauricio Ribeiro & l & \\
\hline 2006 & Dança e Tocatta & Henrique Rebouças & l & \\
\hline 2006 & Anapoesis & Paulo C. Rocha & I & $\begin{array}{l}\text { Inclui texto } \\
\text { falado }\end{array}$ \\
\hline 2007 & Entre o pesar e a leveza & Arthur Rinaldi & l & \\
\hline 2007 & Sonhos & Arthur Rinaldi & I & $\begin{array}{l}\text { Inclui texto } \\
\text { falado }\end{array}$ \\
\hline 2007 & O sublime & Charles A. B. Leandro & l & \\
\hline 2007 & Abstrações I & Ivan Chiarelli Monteiro & l & \\
\hline 2007 & Sumaré & Ivan Chiarelli Monteiro & I & \\
\hline 2007 & Tetragrammaton VI & Roberto Victorio & l & \\
\hline 2007 & Quatro instantâneos & Roberto Victorio & l & \\
\hline 2007 & Anamorfoses & Sérgio Freire & l & $\begin{array}{l}\text { Com live } \\
\text { electronics e } \\
\text { gongos } \\
\text { adicionais }\end{array}$ \\
\hline 2007 & O crescente & Tiago de Mello & l & \\
\hline 2008 & Ijexá pro Bin Laden & Alexandre Espinheira & l & \\
\hline 2008 & Prelúdios No. 1 a 5 & Carlos dos Santos & l & \\
\hline 2008 & Noturno No. 1 & Carlos dos Santos & I & \\
\hline 2008 & $\begin{array}{l}\text { Cirandas Brasileiras. Dê- } \\
\text { me cá sua mão }\end{array}$ & Carlos dos Santos & I & \\
\hline
\end{tabular}




\begin{tabular}{|c|c|c|}
\hline 2008 & Blues para um anjo & Carlos dos Santos \\
\hline 2008 & Dissolução & Charles A. B. Leandro \\
\hline 2008-2009 & Solitude & Samuel Peruzzolo \\
\hline ** & Imagens & Alberto Di Mauro \\
\hline$* *$ & Pingo & Edson Gianesi \\
\hline$* *$ & $\begin{array}{l}\text { Para a maninha dormir } \\
\text { (Acalanto) }\end{array}$ & $\begin{array}{l}\text { Kleber Alexandre } \\
\text { "Anna Maria Vienna" } \\
\text { (Pseud.) }\end{array}$ \\
\hline$* *$ & $\begin{array}{l}\text { Para a maninha acordar } \\
\text { (Acalanto) }\end{array}$ & $\begin{array}{l}\text { Kleber Alexandre } \\
\text { "Anna Maria Vienna" } \\
\text { (Pseud.) }\end{array}$ \\
\hline$* *$ & Fantasia para vibrafone & Luiz D’Anunciação \\
\hline$* *$ & Plainte (Lament) & Marco Pereira \\
\hline$* *$ & Âmago & Rui Carvalho \\
\hline
\end{tabular}
Abreviações
* : composição da década de 1990
** : informação não encontrada
I : material não publicado 